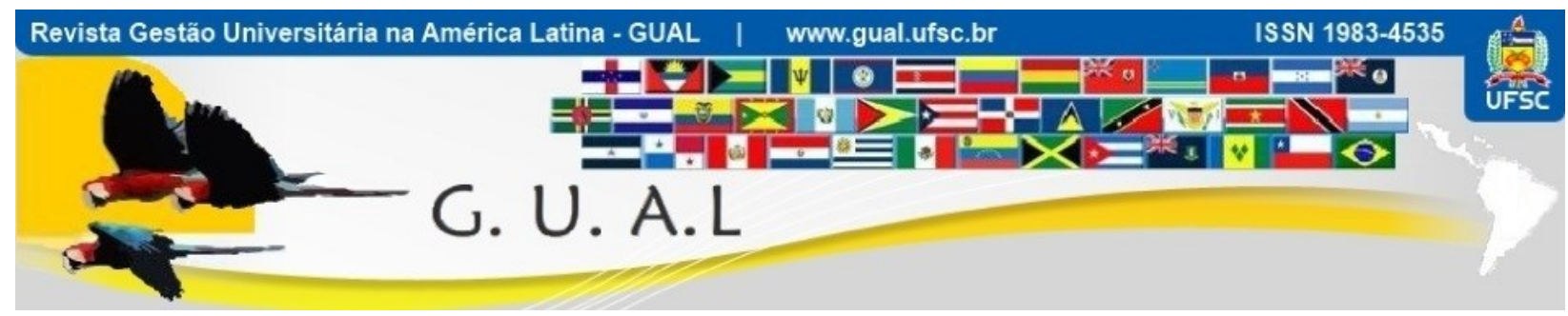

DOI: http://dx.doi.org/10.5007/1983-4535.2015v8n1p260

\title{
FUNÇÕES DE CONFIANÇA NA GESTÃO UNIVERSITÁRIA: A DINÂMICA DOS PROFESSORES- GESTORES NA UNIVERSIDADE FEDERAL DE VIÇOSA
}

\begin{abstract}
FUNCTIONS OF CONFIDENCE IN HIGHER EDUCATION MANAGEMENT: THE DYNAMICS OF TEACHERS-MANAGERS IN FEDERAL UNIVERSITY OF VIÇOSA
\end{abstract}

Rafael Morais Pereira, Graduando Universidade Federal de Viçosa - UFV rafael.morais@ufv.br

Humberto Rodrigues Marques, Graduando Universidade Federal de Viçosa - UFV humberto.marques@ufv.br

Fernando Luiz de Castro, Graduando Universidade Federal de Viçosa - UFV fernando.luiz@ufv.br

Marco Aurélio Marques Ferreira, Pós-Doutor Universidade Federal de Viçosa - UFV marcoaurelio@ufv.br

Recebido em 27/julho/2013

Aprovado em 26/novembro/2014

Sistema de Avaliação: Double Blind Review

Esta obra está sob uma Licença Creative Commons Atribuição-Uso. 


\title{
RESUMO
}

No desenvolvimento da administração pública brasileira destaca-se a relevância dos servidores, tanto àqueles admitidos por aprovação em concurso público quanto àqueles indicados pelo critério de confiança. Esses últimos estão presentes em diferentes órgãos públicos, inclusive nas universidades federais, sendo ocupados por professores que passam a atuar como gestores, além de realizarem atividades de pesquisa, ensino e extensão. Diante disso, este artigo teve como objetivo analisar a dinâmica das funções de confiança existentes na Universidade Federal de Viçosa, problematizando sobre a capacitação dos docentes para exercerem funções gerenciais. Esta pesquisa apresentou uma abordagem qualitativa, de cunho descritivo, com coleta de dados por meio de entrevistas, do Portal Transparência e da Plataforma Lattes. Os resultados demonstraram uma quantidade expressiva de 613 funções de confiança na UFV, sendo 58 delas de cargos de direção. Além disso, os dados secundários e a perspectiva dos entrevistados comprovaram que os docentes não estão preparados para atuarem na gestão, visto que não possuem uma formação específica em administração, mas em outras áreas. Portanto, perante a limitação de criação de cargos para administradores pela instituição, cabe aos professores-gestores buscar novas competências, visando atingir os objetivos de suas novas funções com efetividade.

Palavras-chave: Administração Pública. Funções de Confiança. Gestão Universitária. Professores-Gestores.

\begin{abstract}
In the development of the Brazilian public administration emphasizes the relevance of servers, both those admitted by approval in a public tender as those indicated by the criterion of confidence. The latter are present in different government agencies, including the federal universities, are filled by teachers who start to act as managers, in addition to performing research activities, teaching and extension. Thus, this article aimed to analyze the dynamics of the functions of confidence existing in the Federal University of Viçosa, questioning about the training of teachers to exercise managerial functions. This research presented a qualitative approach and descriptive research, collecting data through interviews, the Portal da Transparência and Plataforma Lattes. The results showed a significant amount of 613 positions of confidence at UFV, 58 of them from leadership positions. In addition, secondary data and the prospect of respondents confirmed that teachers are not prepared to work in management, since they do not have specific training in administration, but in other areas. Therefore, given the limitation of creating positions for administrators by the institution, it is for teachers-managers seek new skills, aiming to achieve the objectives of their new roles with effectiveness.
\end{abstract}

Keywords: Public Administration. Functions of Confidence. Higher Education Management. Teachers-Managers. 


\section{INTRODUÇÃO}

A administração pública é formada por um conjunto de agentes, serviços e órgãos, instituídos pelo Estado com o objetivo de fazer a gestão de determinadas áreas, tais como saúde, segurança, educação e diversas outras mais, garantindo, assim, a oferta de serviços que são de monopólio do mesmo, bem como outros que não são de interesse das empresas privadas. De acordo com Di Pietro (2012) a administração pública, analisada em seu aspecto subjetivo, pode ser compreendida como um conjunto de órgãos e de pessoas jurídicas para os quais o exercício da função administrativa do Estado é atribuído por meio de lei. Historicamente, a administração pública no Brasil pode ser entendida em três modelos, são eles: patrimonialista, burocrático e gerencial.

O modelo patrimonialista apresentou como características marcantes a corrupção, o nepotismo e a confusão entre o patrimônio público e o privado. Ele vigorou no Brasil no período imperial, no qual a administração era operacionalizada para atender aos interesses dos governantes (TORRES, 2007). A administração burocrática, por sua vez, foi introduzida no país em 1936 e se destacou pela ideia de racionalidade, de ponderação entre meios e fins e de precisão, passando também a valorizar o mérito dos funcionários da administração pública. Por fim, o modelo gerencial, mais alinhado à nova dinâmica do mercado internacional, pautado nas relações comerciais globais e o constante desenvolvimento tecnológico, trouxe como base as prioridades na eficiência, concentração nos resultados, qualidade na prestação dos serviços públicos, bem como a redução de custos (PAES DE PAULA, 2005).

É importante que se tenha em mente a não totalidade do rompimento de um modelo com aquele que o precede, sendo que, desta forma, a administração gerencial manteve algumas características da administração burocrática tais como a admissão por critérios de mérito, sistemas estruturados e universais de remuneração, as carreiras, bem como as avaliações de desempenho e o treinamento dos servidores públicos.

Neste contexto de desenvolvimento da administração pública ao longo da história do Brasil deve-se analisar a importância dos servidores públicos para o funcionamento da "máquina" pública, sendo eles os responsáveis por executar as políticas públicas traçadas em cada um dos modelos supracitados. Os servidores públicos possuem um papel relevante na estrutura do Estado, pois eles atuam como membros de transformação do mesmo, tendo como objetivo principal o atendimento dos anseios da sociedade, a partir da ótica do bem comum. 
Assim, a garantia do atendimento desses anseios se relaciona com a constante capacitação dos servidores públicos, por meio de programas de treinamento e desenvolvimento.

Consoante a isso, Amaral (2006) cita a nova política de capacitação e de desenvolvimento de pessoas (Decreto $n^{0} 5.770$ de 23/02/2006) como sendo uma referência chave na política de capacitação dos servidores públicos, pois estimula a aprendizagem e a disseminação do conhecimento, atribuindo ao mesmo a chave para a inovação e a melhoria da gestão pública, por meio de eventos de capacitação que abrangem cursos presenciais e a distância, grupos formais de estudo, intercâmbios, estágios, seminários e congressos.

Entretanto, deve-se observar que, por funcionários públicos, entendem-se tanto aqueles que assumem os cargos por meio de aprovação em concursos públicos, que se tornaram obrigatórios a partir da $\mathrm{CF} / 88$, como aqueles indicados para assumir determinados cargos sem a necessidade prévia de se prestar concurso. Desta forma questiona-se sobre a garantia da ocorrência de capacitação voltada também para os profissionais que ocupam funções de confiança na administração pública.

Nessa perspectiva torna-se importante destacar, sob o aspecto legal, o que são as funções de confiança. Para Rocha (2010), conceitua os cargos de confiança como sendo aqueles que são exercidos pelos empregados, a quem o empregador confere uma especial confiança ou uma maior carga de responsabilidade e de representação.

A existência desses cargos na esfera pública se dá em diferentes instituições, sejam na administração pública direta, através dos ministérios e secretarias ou na indireta, por meio das autarquias, fundações, empresas públicas, entre outras. Nas Instituições Federais de Ensino Superior (IFES), pautadas pela complexidade em suas organizações, visto que lidam com atividades de pesquisa, ensino, extensão e outras mais, observa-se, via de regra, a ocupação dos cargos de confiança por profissionais que atuam também como professores das mesmas IES.

Considerando as universidades, a partir da Universidade Federal de Viçosa (UFV), este artigo teve como objetivo geral analisar a dinâmica das funções de confiança existentes dentro dessa instituição, problematizando sobre a capacitação dos docentes para o exercício de funções de gestores. Além disso, buscou-se verificar se há, em seus processos individuais de formação, cursos direcionados que os habilite, tecnicamente, a assumir funções de confiança. 
Os objetivos específicos, por sua vez, foram: realizar um mapeamento de todas as funções de confiança existentes na UFV, comparando com a totalidade dos cargos; analisar o perfil de formação dos docentes que atuam em funções de confiança da instituição; analisar a dinâmica das funções de confiança na gestão universitária, considerando a preparação para esses cargos, a partir da percepção de quatro atores estratégicos.

\section{FUNÇÕES DE CONFIANÇA NA ADMINISTRAÇÃO PÚBLICA}

A Constituição Federal de 1988 (CF/88) é considerada um marco em termos do provimento dos cargos públicos no Brasil, uma vez que tornou obrigatória, em seu artigo 37, a aprovação prévia em concurso de provas ou de provas e títulos. O texto constitucional tornouse uma barreira para as práticas clientelistas e nepotistas que assolaram o histórico dos cargos públicos no país, pois, como argumenta Carvalho (2011, p. 01), “é cediço que o acesso aos cargos públicos em nosso país sempre foi privilégio para poucas pessoas, principalmente daquelas que possuíam um padrinho que as conduzisse".

As atenções se voltaram para as funções de confiança, visto que essas continuaram a ser ocupadas pela livre decisão dos administradores públicos, nos termos previstos no dispositivo constitucional. Entretanto, para Borges (2012, p. 46), "a denominação funções de confiança tem gerado confusão terminológica e falta de uniformidade nos conceitos, em razão de sua utilização ora como gênero ora como espécie, bem como da ausência de uma definição precisa". Nesse sentido, a autora define funções de confiança como gênero, o qual comporta as espécies cargos em comissão e funções de confiança stricto sensu (em sentido estrito).

Tanto os cargos em comissão quanto as funções de confiança stricto sensu se caracterizam pela confiança depositada em seu ocupante, assim como, pelo caráter transitório de vínculo com a Administração Pública e pelo exercício de atividades de direção, chefia ou assessoramento (BORGES, 2012; CF, 1988; MPOG, 2008). A espécie cargos em comissão, denominada também cargos comissionados ou cargos de confiança, tem por base a definição de cargo público, expressa pela Lei $\mathrm{n}^{\mathrm{o}}$ 8.112/90, como “o conjunto de atribuições e responsabilidades previstas na estrutura organizacional que devem ser cometidas a um servidor" (BRASIL, 1990).

Em relação aos benefícios dos cargos de confiança, Carvalho (2011) e Santos (2009) sustentam que são determinantes para que a administração não se torne estática, mas orgânica e voltada para a continuidade das políticas públicas, pois corroboram para atender as 
necessidades da sociedade que se tornam cada vez mais complexas. Reitera-se, portanto, que “esses cargos (e funções) são de suma importância para atuação da administração pública enquanto fornecedora de serviços, mas, sempre para atender aos interesses públicos" (CARVALHO, 2011, p. 04).

Destarte, diferenciam-se dos cargos em comissão as funções de confiança stricto sensu (funções comissionada ou função gratificada), uma vez que essas consistem num conjunto de atribuições especiais exercidas por servidores, que não constituem uma nova unidade na máquina pública. Portanto, segundo Graef (2010, p. 03), “as funções são acréscimos de responsabilidades de natureza gerencial ou de supervisão atribuídas ao servidor ocupante de cargo efetivo, tendo como referência a correlação de atribuições".

Na definição apresentada acima, destaca-se a importância da correlação de atribuições entre o cargo ocupado e as atividades a serem exercidas pelo servidor na função comissionada, uma vez que, se não houver correlação, é justificável a criação de um novo cargo e não de uma função. Essa pressuposição é essencial, visto que possibilita

que a experiência adquirida ao longo da vida funcional de um servidor, no exercício de suas atribuições em atividades técnicas, se constitua em elemento relevante, para que possa se habilitar para o exercício de uma função gerencial. Nesta perspectiva, a função gerencial se torna um prolongamento, por acoplamento, da atividade técnica (GRAEF, 2010, p. $05)$.

Assim, seja nas funções gratificadas ou nos cargos em comissão faz-se necessário que as pessoas sejam selecionadas para além dos fatores confiança e experiência técnica. Nesse sentido, Borges (2012, p. 51) é enfática, ao afirmar que "não é compatível [...] o provimento de funções de confiança por pessoas destituídas de qualquer predicado objetivo, como habilitação, capacitação ou virtude, necessário ao desempenho da função pública".

A capacidade de interlocução com atores estratégicos, o alto grau de educação formal, a meritocracia e a notória experiência profissional são outros fatores que também devem ser considerados (BORGES, 2012; MPOG, 2008). Conclui-se que, para o exercício dessas funções gerenciais, é determinante a aquisição de novas competências, como "capacidade de trabalhar em equipe, a capacidade de articulação e negociação e, principalmente, o desenvolvimento da capacidade de liderança entre seus pares" (GRAEF, 2010, p. 05).

Nesse contexto, ressalta-se a importância da profissionalização da administração pública, inclusive para as funções de confiança. A partir disso, as ações das organizações 
públicas serão mais racionais, preconizando o interesse coletivo, pois a profissionalização implica numa redução de práticas clientelistas (SANTOS, 2009). Partindo das conclusões de Santos (2009, p. 22), que afirma que "a administração pública brasileira tem avançado de maneira muito lenta no sentido de sua ocupação de forma profissionalizada", discuti-se a seguir a importância do processo de capacitação dos gestores públicos.

Para Newcomer (1999), o primeiro fator a se considerar no processo de profissionalização pública é que o aprendizado consiste num processo contínuo, para tanto os gerentes públicos precisam compreender tal perspectiva. Corroborando com essa acepção, Amaral (2006, p. 549) reitera que "o aperfeiçoamento permanente de servidores poderá contribuir muito para a melhoria da qualidade do serviço público". No âmbito mundial, percebe-se que em países mais desenvolvidos, o processo de profissionalização da gerência pública se encontra mais avançado, com vistas à modernização da máquina estatal. Os instrumentos utilizados podem ser diversos, como

órgãos especializados dentro da administração para a capacitação de todos os funcionários; organismos externos autônomos que se especializam na formação de altos gerentes (do tipo da famosa Escola Nacional de Administração da França); programas universitários de pós-graduação; bolsas governamentais ou de cooperação para estudos no exterior; cursos especiais dirigidos a gerentes públicos, etc. (TOHA; SOLARI, 1997, p. 95).

Destaca-se, nesse cenário, a Inglaterra, que possui um serviço público consistente, em que os cargos de confiança passaram a ser ocupados por administradores capacitados e engajados politicamente em atingir os objetivos do governo. Já em países menos desenvolvidos, como os latino-americanos, as ações ainda são incipientes, visto que os cargos públicos são ocupados ora por profissionais de carreira sem capacidade gerencial ora por executivos de baixo perfil político (TOHA; SOLARI, 1997).

No Brasil, um avanço considerável foi a criação da Escola Nacional de Administração Pública, em 1986, que tem como objetivo oferecer formação e aperfeiçoamento em Administração Pública a servidores públicos federais (ENAP, 2014). Contudo, como ressalta Bernardoni (2010, p. 50), o histórico das "políticas de gestão de recursos humanos na administração pública brasileira é marcada por uma série de descontinuidade e por dificuldades significativas referentes à estruturação dos seus principais sistemas".

Os desafios a serem enfrentados retomam a discussão acerca da aproximação entra a administração privada e pública. Numa análise comparativa, Smith (2003, p. 108) afirma que 
os gestores do âmbito privado "estão muito mais convencidos da utilidade de se capacitarem. Eles certamente gastam mais tempo nisso. No governo com gerentes há mais um senso de estado de cerceamento, que, se eles não se capacitarem, muito pode dar errado". Assim, devese incentivar uma mudança no perfil dos administradores públicos, visando capacidades gerenciais específicas e aspectos comportamentais, como a liderança.

Portanto, o caráter mais dinâmico e complexo da esfera pública exige, por de seus administradores, atitudes mais condizentes com essa realidade, na qual a profissionalização é elemento preponderante. Além disso, as funções de confiança, considerando as ressalvas apresentadas, são também essenciais para a organicidade do âmbito público, tanto que "a criação desses cargos é inerente à organização administrativa de cada poder" (CARVALHO, 2011, p. 06). Assim, ressalta-se que as práticas de profissionalização dos servidores públicos devem abranger as funções de confiança, de modo a proteger os interesses da sociedade com o cumprimento dos princípios constitucionais que norteiam a administração pública.

Com o objetivo de aprofundar as discussões sobre funções de confiança e profissionalização, apresenta-se na seção seguinte a gestão universitária no país, haja vista a amplitude de sua complexidade e sua importância no contexto atual.

\section{GESTÃO UNIVERSITÁRIA E PROFESSORES-GESTORES}

Os constantes avanços nos ambientes em que as organizações estão inseridas fazem com que elas busquem novas estratégias e modelos de gestão, de modo a se tornarem mais eficazes e competitivas. Machado e Silveira (1998) apud Souza (2003) enfatizam que as Instituições de Ensino Superior (IES), que também estão submetidas a essas transformações no ambiente, devem propor mudança, tornando-se mais flexíveis e ágeis, como forma de otimizar seus recursos, de modo a obter melhores resultados e atingir seus objetivos.

Ainda, segundo Souza (2003), as IES são consideradas complexas, uma vez que exercem várias atividades, dentre elas a pesquisa, o ensino e a extensão. Nesse sentido, Grillo (1996) apud Bernardes (2003) corrobora ao enfatizar que por essas instituições serem complexas e possuírem objetivos variados, elas devem possuir um modelo de gestão que não se baseie apenas nos modelos de empresas, mas que também seja voltado para a criação e difusão do conhecimento, que é o seu objetivo principal.

As IES, apesar de possuírem objetivos diferentes de instituições econômicas, também necessitam de práticas de gestão eficientes para atingirem seus resultados, de modo que haja 
sempre uma interação entre todas as partes envolvidas da organização (LOPES, 1999; PALMEIRAS; SZILAGYI, 2011). Para tanto, Sampaio e Laniado (2009) elencam de acordo com a renovação dos modelos administrativos relacionados à gestão universitária, algumas críticas, como a burocratização, a fragmentação departamental, aos mecanismos de participação e decisão de colegiados, assim como a autonomia como princípio acadêmicoadministrativo como forma de melhorar a racionalidade administrativa, a eficiência na alocação de recursos, a qualificação de pessoal, entre outros.

Verifica-se, para tanto, que esses gestores, responsáveis por ocupar os cargos de chefia dentro das IES e responsáveis por administrar a instituição, ocupam, em sua grande maioria, cargos de professores, também dessas organizações (PALMEIRAS; SZILAGYI, 2011; MARRA; MELO, 2003). Segundo Silva (2000) apud Marra e Melo (2003), a transição de professor para administrador faz com que o indivíduo não atue apenas na área acadêmica, assim como também não proporciona a esse indivíduo instituir a gestão como seu trabalho central, logo ele continua atuando como professor, porém com uma nova identidade profissional, a de gerente.

A crítica a esse modelo de gestão das IES se refere à falta de capacitação desses docentes ao assumirem cargos de gestão, já que na maioria das vezes eles são formados em áreas que não proporcionam aos mesmos uma habilitação em práticas gerenciais, uma vez que possuir a titulação de doutorado não prepara alguém para ser gestor universitário (KANAN; ZANELLI, 2011; SILVA, 2012; SILVA, 2000 apud GONÇALVES, 2010; MARRA; MELO, 2003; MEYER JR., 2000 apud SOUZA, 2003). Consoante a isso, Grillo (1996) apud Kanan e Zanelli (2011) enfatiza que a universidade perde a atuação de um bom professor para adquirir um gestor que não possui preparação para assumir o cargo, aprendendo muitas vezes, de acordo com Marra e Melo (2003), por erros e acertos.

Assim, Walter et al. (2007) apud Palmeiras e Szilagyi (2011) revelam que estudos demostram que a gestão universitária possui suas funções diluídas em práticas sociais, assim como indefinições, falta de planejamento e constantes improvisações, o que remete a uma gestão frágil. As IES não usufruem do conhecimento gerado nos cursos de gerenciamento, como evidenciado por Meyer Jr. (2003) apud Gonçalves (2010, p. 73), as IES "formam administradores para dirigir outras organizações, ensinam-lhes teorias, técnicas e abordagens que não são utilizados na sua própria administração". 
No entanto, Palmeiras e Szilagyi (2011, p. 3) afirmam que "a área educacional universitária tem buscado maior profissionalização de seus cargos gerenciais a partir da necessidade do gestor na área educacional de conciliar a gestão administrativa, pedagógica, acadêmica e científica”. Entretanto, Silva, Moraes e Martins (2003) apud Gonçalves (2010) afirmam que o aprendizado gerencial desses professores não advém apenas de programas voltados para o desenvolvimento ou da educação gerencial desses, uma vez que a prática realizada no dia a dia também se constitui em uma importante fonte de aprendizagem.

Pôr os cargos de gerências exercidos por professores nas IES serem temporários, esse docente pode assumir, ao longo de sua trajetória acadêmica, vários cargos de gestão (SILVA, 2012), dentre esses a coordenação de curso, a chefia de departamento, as diretorias das unidades administrativas, os órgãos de apoio e de assessoria, os cargos em pró-reitorias ou reitoria, entre outras áreas (SILVA, 2012, MENDES, 2001, GONÇALVES, 2010, MARRA e MELO, 2003). Ainda com relação à gestão nas IES, de acordo com Gonçalves (2010, p. 72)

\footnotetext{
deve-se levar em consideração que os cargos administrativos nas IES são considerados "cargos de confiança" e que, portanto, a qualquer momento, este gestor pode voltar a ocupar somente a função de professor na instituição, não caracterizando ante à legislação trabalhista vigente, um rebaixamento de função do profissional.
}

Surge, para tanto, a discussão acerca do papel desempenhado pela gestão de recursos humanos $(\mathrm{RH})$ dentro das organizações, como fator facilitador de práticas relacionadas às competências e capacidades desses gestores. Afinal,

as pessoas constituem a essência de qualquer instituição ou organização. Em se tratando de instituição universitária, cujo insumo básico é a inteligência, elas são então, ao mesmo tempo, a matéria-prima e o instrumento da produção intelectual. Em nenhuma outra organização o elemento humano é tão importante. Assim, o investimento prioritário e maior de uma universidade deveria ser nos seus recursos humanos. (BERNARDES, 2003, p. 3)

Pressupõe-se que práticas de RH, como recrutamento e seleção, avaliação de desempenho, treinamento e desenvolvimento e relações no trabalho precisam ser reformuladas, para alavancar a eficácia das IES (MENDES, 2001). Palmeiras e Szilagyi (2011) ressaltam a importância do desenho de cargos, pois, para que os gestores universitários possam desempenhar suas funções com eficiência é preciso saber quais atividades devem realizar, assim como os papéis gerenciais assumidos no ato de seu cargo. Para esses autores, 
essa identificação colabora na definição das competências essenciais para um gestor na educação superior.

Algumas competências devem estar inerentes a esses gestores, sendo elas tanto de ordem técnica como pessoais, que assumem durante suas gestões uma multiplicidade de papéis. As técnicas referem-se à gestão de recursos escassos, à visão de futuro, à disposição de mudança, à visão estratégica, à capacidade de decisão, ao gerenciamento de informações, entre outras. Com relação a pessoais, identifica-se a administração de conflitos, a coordenação de pares, a confiança, a liderança, a orientação de pessoas, a capacidade de relações públicas, entre outros (SILVA, 2012; GONÇALVES, 2010; MINTZBERG, 1995 apud CAMPOS et al. (2008); MEYER Jr., 2000 apud MARRA e MELO, 2003).

Diante da importância que os professores assumem na gestão universitária atual, não se pode desconsiderar o processo de profissionalização, visto que esses necessitam adquirir competências complementares para atuar nesse novo papel. Marra e Melo (2003, p. 13) reforçam a importância do conhecimento, uma vez que "em geral, o docente não reconhece o gerente como uma posição de chefia. A hierarquia na Universidade é a hierarquia do conhecimento. O mais forte e reconhecido é aquele que publica mais, que pesquisa mais".

Ademais, há de se reiterar que os docentes-gestores são funções de confiança, que preconizam o bom relacionamento com grupos de interesses diversos. Tanto aqueles que selecionam os gestores quanto aqueles que passam a exercer essa função, devem ter como uma prerrogativa o interesse coletivo. Afinal, dada a importância que as universidades exercem no desenvolvimento do país, elas devem ser um exemplo para as demais instituições públicas no que se refere ao gerenciamento das funções de confiança.

\section{PROCEDIMENTOS METODOLÓGICOS}

O presente estudo, que visou analisar a dinâmica das funções de confiança na gestão universitária atual, na perspectiva de uma instituição federal de ensino superior de Minas Gerais, apresentou como abordagem mais adequada a perspectiva qualitativa, com caráter descritivo. Visto que a "pesquisa qualitativa é aquela que trabalha predominantemente com dados qualitativos, isto é, a informação coletada pelo pesquisador não é expressa em números, ou então os números e as conclusões neles baseadas representam um papel menor na análise" (DALFOVO, LANA, SILVEIRA, 2008, p. 09). 
Os dados utilizados foram tanto primários quanto secundários. Os secundários foram coletados no Portal Transparência, da Controladoria Geral da União do Governo Federal, onde identificou-se 58 cargos de direção e 111 cargos de coordenador de curso na UFV. Ainda, utilizou-se o a Plataforma Lattes para identificar certas características na formação desses. Por fim, quanto aos dados primários, foram realizadas 4 entrevistas, 3 sendo ocupantes de cargos de confiança na UFV, um coordenador de curso, um ex-diretor de centro e um pró-reitor, além de um professor especialista em gestão universitária.

A análise dos dados ocorreu de forma interpretativa, com suporte no referencial teórico da seção anterior. A seguir são apresentados os resultados encontrados na pesquisa, divididos em duas partes, a primeira referente ao Provimento de cargos públicos e as funções de confiança na UFV e a segunda referente ao Professores-gestores, competências e profissionalização na UFV.

\section{PROVIMENTO DE CARGOS PÚBLICOS E AS FUNÇÕES DE CONFIANÇA NA UFV}

A obrigatoriedade do concurso para o provimento de cargos públicos no Brasil, estabelecida pela $\mathrm{CF} / 88$ e regida pela Lei $\mathrm{n}^{\circ}$ 8.112/90, delineou um realinhamento e uma nova perspectiva em todos os órgãos públicos brasileiros. Como suscitado por Bresser Pereira (1996, p. 14), “o grande mérito da Constituição de 1988 foi ter tornado obrigatório o concurso público para a admissão de todo e qualquer funcionário. Este foi sem dúvida um grande avanço, na medida que dificultou o empreguismo público". Assim, distinguem-se dois momentos de adesão à carreira pública no país, antes e após a constituição, que se caracterizaram, inclusive, no âmbito das universidades federais.

No primeiro cenário, em relação à UFV, os concursos eram realizados quando necessário, entretanto, como apresentado pelo pró-reitor, era apenas para "dar satisfação para a sociedade, atender uma demanda, mas mesmo assim não se respeitava muito esses resultados dos concursos públicos, existiam algumas nomeações, contratações paralelas. E, ainda, também, não existia transparência”. Evidencia-se, assim, a existência de práticas de favorecimento que permearam todo o histórico de ingresso no serviço público no país (CARVALHO, 2011).

Após a regulamentação, para o pró-reitor, o cenário foi demarcado por uma maior fiscalização, de modo que a folha de pagamento da universidade tornou-se competência do 
Ministério do Planejamento e todos os atos administrativos passaram a ser auditados. Nesse sentido, essas medidas normativas são vistas de forma positiva pelo ex-diretor de centro, pois segundo ele, essa legislação própria instituída é "bastante produtiva, porque é uma legislação que disciplinou, organizou e estruturou, de uma forma bem geral, o emprego no serviço público".

Em contrapartida, destaca-se como um aspecto negativo dessa reconfiguração no serviço público os fatores relacionados ao plano de carreira, uma vez que ele não apresentou uma evolução e houve, ainda, a extinção do concurso interno nos órgãos federais. Assim, nesse aspecto destaca-se a influência da legislação sobre a gestão universitária, incluindo o provimento de administradores, visto que há uma dependência das universidades frente ao Congresso Nacional, que detém o poder exclusivo de criação de novos cargos. O pró-reitor expõe essa dificuldade existente no âmbito da UFV

[...] é um plano de carreira antigo, e não contempla, por exemplo, a mão-deobra que a gente está precisando, então é um plano engessado, você pode ter tantos técnicos de nível superior. [...] a gente tem hoje um número limitado de administrador [...] de repente eu falo assim, "eu quero que todas as pessoas sejam administradoras aqui dentro da instituição", eu não posso fazer isso porque eu tenho esse número limitado, esses cargos são criados pelo Congresso, então a gente tem pouco cargo (PRÓ-REITOR).

$\mathrm{O}$ ingresso na carreira pública se caracteriza, portanto, como um dos fatores que diferenciam a administração pública da administração privada. Além disso, para Grillo (1996) apud Bernardes (2003), a gestão universitária deve ir além dos modelos de outras instituições públicas e das empresas privadas, pois tem como objetivo final a geração e a transmissão do conhecimento. Nessa mesma acepção, o professor especialista em gestão universitária reitera que "é importante considerar que a gestão universitária, pelo seu objetivo social, é diferente da administração de empresas" e, em consonância, o coordenador de curso sustenta que "usar ferramentas de empresa privada na área pública é muito complexo. Os objetivos são todos diferentes".

Além de toda essa complexidade no âmbito da gestão universitária, cabe destacar, a coexistência das funções de confiança, as quais são permitidas pela constituição e ocupadas por livre escolha dos administradores (BORGES, 2012). Na perspectiva dos entrevistados é unânime a importância das funções de confiança, como justificativa, o professor especialista em gestão universitária defende que o reitor "precisa de pessoas que se comprometam com a 
sua perspectiva política. Já pensou se o governo federal tivesse que abrir concurso para próreitor ou para exercer os cargos de ministros da presidência".

A necessidade das funções de confiança é sustentável, porque, para o ex-diretor de centro, "a responsabilidade do gestor público é muito grande" e, para o coordenador de curso, porque "muitas vezes entra para ser auxiliar da gente pessoas que nem sempre estão aderentes com o objetivo que você pretende atingir naquela gestão". Nesse sentido, referendam-se as pressuposições de Carvalho (2011) e Santos (2009), de que essas funções conferem uma maior organicidade para a gestão pública na consecução de seus objetivos, que se originam de demandas cada vez mais complexas.

Quanto aos pontos negativos, o pró-reitor, destaca o perfil inadequado de alguns servidores para esses cargos, pois, na maioria das vezes, são selecionados apenas pelo caráter político, o que gera um mal estar na comunidade acadêmica. Outro ponto controverso na literatura se refere ao número existente de funções de confiança no país, como apresentado por Carvalho (2011, p. 06), há ainda a "criação de cargos em número superior ao necessário para atender aos interesses da administração". Na UFV, dentre os 3.706 servidores, docentes e técnicos-administrativos, 613 exercem funções de confiança, representando 17\% do total de cargos. A proporção de cargos de direção, funções gratificadas e funções comissionadas de coordenador de curso é representada a seguir (Figura 1).

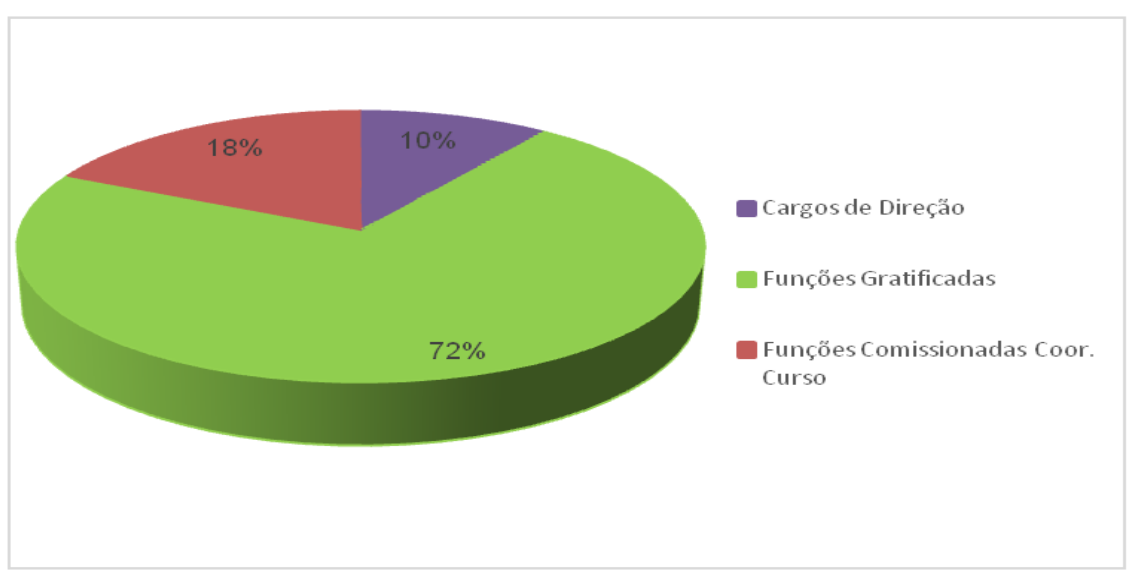

Figura 1 Funções de Confiança na UFV.

Fonte: Portal da Transparência.

A maioria dos entrevistados reconheceu que o número de funções de confiança na UFV é grande, sendo que para o pró-reitor, o número excessivo é justificável nos cargos operacionais, em função da estrutura da universidade. Visão congruente com à do coordenador de curso, que afirma que "a nossa universidade tem uma estrutura extremamente complexa". Ainda, para o pró-reitor, o número de cargos de direção e assessoramento não é 
plausível, assim como para o professor especialista em gestão universitária. Este salienta que “o número de assessores de qualquer Pró-Reitoria é muito grande e, ainda, não há uma uniformidade, algumas têm mais outras têm menos. Gera uma macrocefalia (doença) na gestão universitária”.

Por outro lado, o ex-diretor de centro acredita que a quantidade desses cargos é compreensível, pois "a universidade cresceu muito, então vai expandindo cada vez mais suas atividades, número de cursos, número de departamentos, outros campi”, contudo, ressalta que "não deve ampliar mais, mas a manutenção dos que estão aí, eu acredito que [é justificável] sim". Deve-se, portanto, atentar-se a esse quantitativo, pois "a redução do número de cargos políticos, ou sua estabilização, pode ser um meio para melhorar a capacidade de gestão" (LEWIS, 2007 apud SANTOS, 2009, p.10).

Outro aspecto inerente às funções de confiança, que deve ser considerado, é o vínculo transitório com a administração pública (MPOG, 2008; BORGES, 2012). Nesse sentido, deve-se analisar o comprometimento e a motivação dos ocupantes desses cargos. Na visão dos entrevistados, esses fatores são decorrentes da importância concedida a esses cargos, em alguns casos, pela vontade individual de pessoas que realmente querem contribuir com a instituição, mas na maioria das vezes, é por causa da gratificação financeira. Então, o professor especialista em gestão universitária assevera que são recorrentes os "interesses ‘politiqueiros' e não verdadeiramente políticos nesses cargos de confiança".

Portanto, como salienta o pró-reitor, identifica-se a existência dos "políticos de carreira", que são aqueles que estão sempre presentes em diversas gestões da universidade. Adiciona-se, ainda, o fato deles serem, na maioria das vezes, docentes, que passaram a assumir as diversas funções de gestão na universidade. Assim, na seção seguinte, analisa-se como estão posicionados os docentes-gestores no âmbito da UFV, discutindo a formação deles, assim como o processo de profissionalização e aquisição de competências.

\section{PROFESSORES-GESTORES, COMPETÊNCIAS E PROFISSIONALIZAÇÃO NA UFV}

Como discutido, os professores, além de ocuparem seus cargos de docentes dentro das instituições de ensino, muitas vezes eles também assumem cargos de gestão (PALMEIRAS e SZILAGYI, 2011; MARRA e MELO, 2003). Esse fato é enfatizado pelo coordenador de curso, uma vez que "você é contratado para ser professor, a sua essência é dar aula, mas 
quando você assina o contrato, você sabe que você tem que dar aula, tem que fazer pesquisa, tem que fazer extensão e tem que ajudar na administração [...]".

Para o professor especialista em gestão universitária é “importante sim que os professores exerçam cargos de gestão, entretanto, na maioria das vezes eles não estão preparados para exercer as funções gerenciais [...]". Campos et al. (2008) caracterizam essa gestão por professores como amadora, já que, além de possuírem a docência como carreira, as IES não promovem uma cultura de treinamento para que assumam esses cargos.

Assim, de acordo com os dados secundários analisados (Figura 2), identifica-se que grande parte dos gestores da UFV possuem titulações de alto nível, sendo que 13\% possuem Pós-Doutorado e $60 \%$ possuem Doutorado. O coordenador de curso acredita que, em alguns casos, por meio da própria formação que esses professores desenvolvem, é possível que desempenhem um papel interessante em cargos de gestão. Contrário a isso, destaca Silva (2000) apud Gonçalves (2010), uma vez que ressaltam que somente a realização de cursos de doutorado em alguma área de conhecimento não capacita gestores universitários.

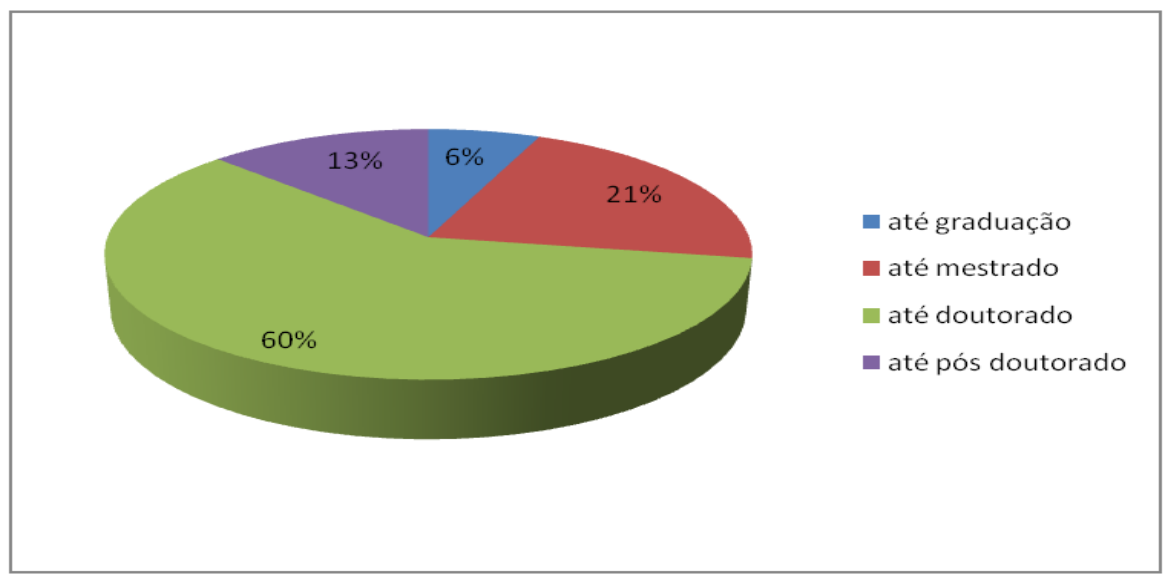

Figura 2 Formação acadêmica dos ocupantes dos cargos de confiança. Fonte: Dados da Pesquisa.

Como enfatizado pelo ex-diretor de centro, "o que se peca muito na universidade é não pôr a pessoa certa no lugar certo. [...] Então, nós temos cargos aí de direção de ponta onde a formação desse ocupante do cargo não é compatível com o desenvolvimento das atividades". Como verifica-se na Figura 3, que refere-se à formação básica, ou seja, à graduação dos gestores de cargos de confiança da UFV, apenas 9\% possuem um curso na área gerencial, em Administração. Os demais possuem uma formação que não proporcionam aos mesmos uma abrangência sobre como gerir. Como argumenta Silva (2012, p. 77) "os atuais administradores 
da educação, na maior parte dos casos, não foram formados para desempenhar papéis de gestores nas Instituições de Ensino em que trabalham”.

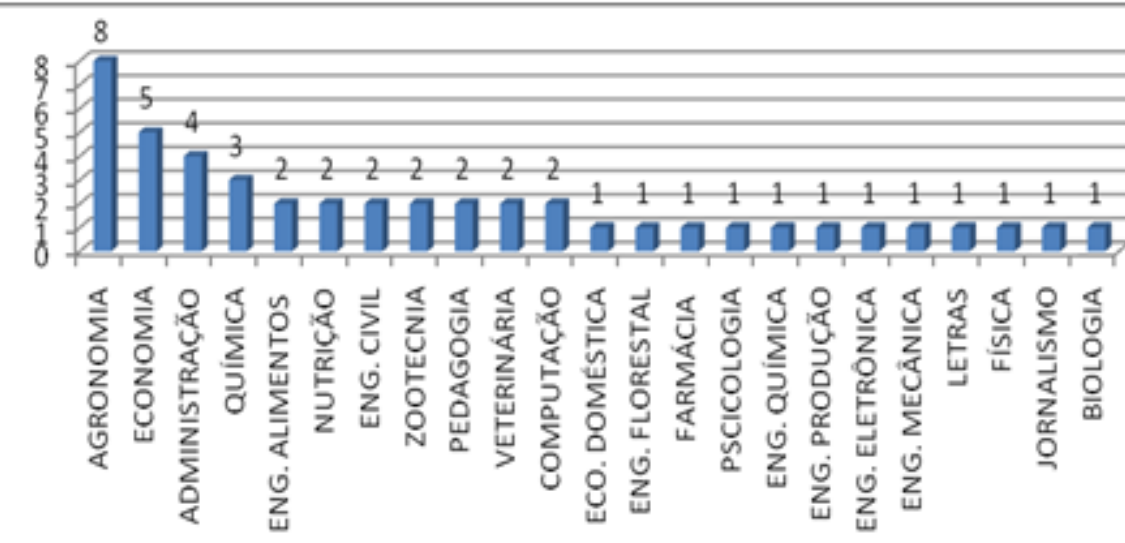

Figura 3 Cursos de graduação dos ocupantes dos cargos de confiança. Fonte: Dados da pesquisa.

Para o professor especialista em gestão universitária "os professores têm a experiência é de realizar pesquisas em seus laboratórios, assim, quando os professores assumem cargos de gestão, a universidade perde ótimos pesquisadores e ganham péssimos gestores", como apresentado por Grillo (1996) apud Kanan e Zanelli (2011) as IES perdem um bom professor para ganhar um gestor despreparado. No entanto, para o pró-reitor, quanto à capacidade de professores-gestores, há uma dependência do local onde ele está e a formação dele. Segundo ele, é importante destacar que há uma equipe que auxilia na gestão desses professores, logo "mesmo você não tendo conhecimento de gestão, [...] você tem uma equipe que dá suporte e você é aquela pessoa que vai fazer a gestão da equipe [...]”.

Para os quatro entrevistados é essencial que os professores possuam certas competências para gerir o cargo. Para o pró-reitor "cada lugar, cada gestão dentro do órgão exige competências diferenciadas. [...] A primeira coisa dentro de uma instituição pública é você conhecer a legislação de cada órgão". Palmeiras e Szilagyi (2011) corroboram nessa perspectiva ao enfatizarem que é essencial a existência do desenho de cargos nas IES, pois é por meio desse que se saberá as atividades de cada cargo, seus papéis gerenciais e suas competências. Para o ex-diretor de centro as capacidades também dependem do cargo que é assumido, sendo que

os Pró-Reitores, os diretores de centro, os diretores de unidades devem ser pessoas que tenham um certo conhecimento de gestão, tenha uma bagagem administrativa, que já foi chefe de departamento, que já foi coordenador de curso, que tenha uma certa experiência, não uma pessoa desprovida de experiência porque senão é muito mais difícil. 
Outra característica desses gestores é que eles devem conhecer a estrutura da organização como forma de melhor se adaptarem ao seu contexto e, assim, saber suas especificidades. Nessa perspectiva aborda o pró-reitor ao afirmar que é necessário “conhecer a história da universidade, mas conhecer a história da universidade é aquele pessoal que já vem de carreira", como os professores.

De acordo com a Figura 4 verifica-se que $70 \%$ dos cargos de confiança da UFV são ocupados por pessoas que realizaram pelo menos uma fase de sua formação na instituição, ou seja, cursaram graduação, mestrado, doutorado ou pós-doutorado na UFV. Esse fato é importante, pois faz com que o docente-gestor já conheça a estrutura e a dinâmica da instituição ao assumir o cargo.

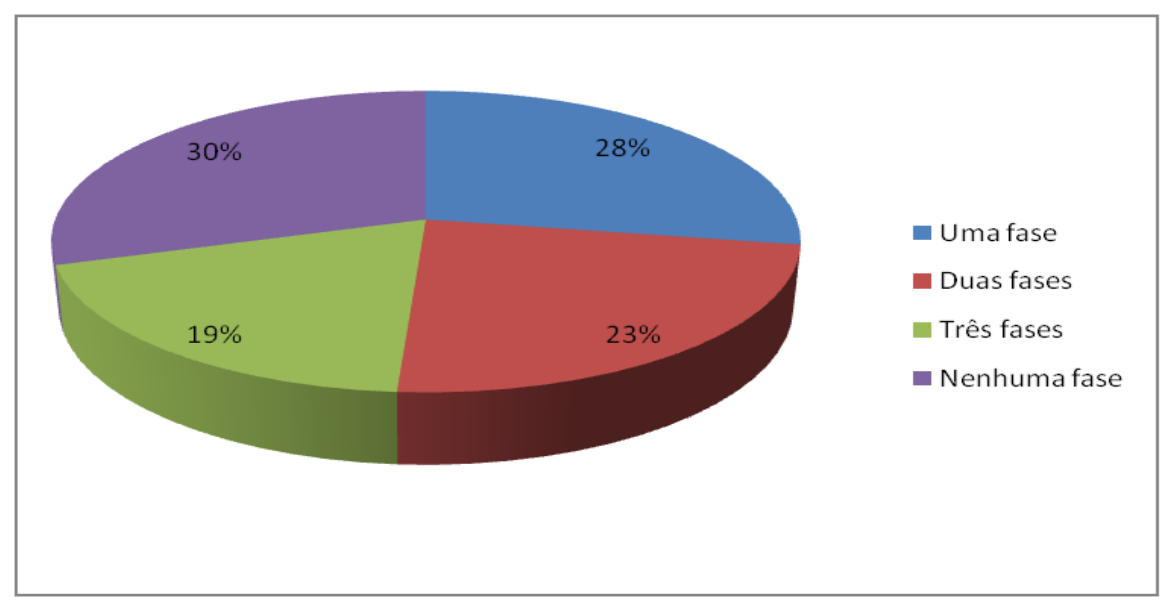

Figura 4 Quantas fases da formação dos professores-gestores aconteceram na UFV.

Fonte: Dados da pesquisa.

Com relação às competências essenciais aos coordenadores de curso, para Kanan (2011, p. 153) "requer dos coordenadores de curso competência técnica, científica e gerencial". Verifica-se, assim, pela fala do coordenador de curso entrevistado que

coordenação de curso é mais burocrático. [...] A questão de um bom relacionamento é importante porque você tem acesso a todos os outros cargos da UFV, você é demandado por todos os outros. Tem também que ter paciência e dedicação com relação a abrir seu espaço de tempo às vezes para as outras atividades burocráticas da própria estrutura que acaba te ocupando demais, então você acaba se dedicando muita a isso e deixando de cumprir outras tarefas, então é por isso que muitas vezes as pessoas não gostam de esse cargo, porque é um cargo que demanda tempo, demanda um pouco de dedicação e atendimento a normas e regras. Basicamente é isso que a gente faz. Tipo assim se você tiver um conhecimento da estrutura UFV, fica relativamente, mais fácil, se você tiver conhecimento das resoluções do que rege a universidade fica mais fácil, então se a pessoa tiver esses conhecimentos ela se encaixa perfeitamente. Mas se ela não tiver, ela vai precisar de alguém que a oriente nesse sentido e que ela sente e faça a leitura. Então não é um cargo que demanda nenhuma habilidade fabulosa. 
Assim, como identificado, por o cargo de coordenador de curso por ser mais burocrático, onde o conhecimento da estrutura, normas e regras contribui para a gestão desse cargo, pôde verificar que dos 111 coordenadores de cursos existentes na UFV, nos três campi, apenas $15 \%$ possuem uma especialização/formação complementar que auxiliaria na gestão do cargo que ocupam. Identifica-se que esses professores buscaram se capacitar de duas formas, tanto na área gerencial com cursos, palestras, seminários relacionados ao aperfeiçoamento de chefia e liderança, em estratégia, em utilização de recursos (materiais, financeiros e humanos), entre outros, quanto na área educacional como na área pedagógica, produção de material didático, relação entre professor e aluno, entre outros.

Como afirma o coordenador de curso e o pró-reitor, a profissionalização é importante para desenvolver habilidades e competências, mas muitas vezes a capacitação ocorre apenas para ganhar um adicional de salário, mas não para contribuir para o setor em que atua. Para o professor especialista em gestão universitária “é importante que o próprio gestor entenda que o treinamento e o direcionamento dos seus subordinados se fazem necessário. Deve partir, então, do gestor a iniciativa para capacitar a sua equipe”. Para Meyer Jr. (2000) apud Campos et al. (2008) os administradores das IES devem se preocupar em buscar habilidades como forma de auxiliar na sua forma de gerir, de modo que desenvolva certas características, essenciais para tal cargo.

Enfim, ao se contrapor o aprendizado gerado pela prática com o proporcionado pela teoria, Silva, Moraes e Martins (2003) apud Gonçalves (2010) enfatizam que o aprendizado gerencial desses professores não advém apenas de programas voltados para o desenvolvimento gerencial ou da educação gerencial, mas também de prática que esses realizam no dia a dia do trabalho. Contrário a isso o ex-diretor de centro, enfatiza que a busca pelo aprimoramento gerencial após o ingresso no cargo, por meio da prática, é prejudicial, uma vez que o gestor passa a aprender sob pressão.

\section{CONSIDERAÇÕES FINAIS}

Os avanços obtidos pela administração pública brasileira em termos de organização da máquina estatal são inegáveis. Contudo, dada à demanda constante por parte da sociedade e à busca por novos modelos de gestão, novos desafios emergem para que se possa legitimar a gestão pública de uma nação. As funções de confiança no âmbito público se configuram, assim, como um novo problema que merece atenção, visto que são contempladas pela exceção 
à regra de concurso público pelo dispositivo constitucional. Caracterizadas, primordialmente, pelo aspecto confiança, mas também pelo vínculo transitório com a administração pública, elas têm sido motivo para questionamentos na literatura especializada. As indagações têm como foco o número excessivo dessas funções e a falta de capacitação dos servidores que assumem esses cargos, inclusive na gestão universitária.

Nesse sentido, as principais conclusões deste estudo, que teve como local de análise a UFV, reiteraram tais pressupostos, uma vez que foi identificada uma quantidade expressiva de cargos, principalmente, nos cargos de direção. Além disso, é explícito que o âmbito da gestão universitária é caracterizado pela atuação dos professores-gestores, ou seja, professores que passam a exercer atividades gerenciais, por meio das funções de confiança. Os dados encontrados, assim como, a perspectiva dos entrevistados, comprovaram que os docentes, em sua maioria, não estão preparados para atuarem na gestão, visto que não possuem uma formação específica em administração (universitária) e, ainda, desenvolvem as demais atividades basilares da instituição, ensino, pesquisa e extensão.

Portanto, o provimento para cargos de gestão, exclusivamente, para administradores seria plausível, entretanto, a interface da administração privada com a pública se rompe, por causa de um fator inexorável, a legislação. Perante a limitação de criação de cargos pela própria instituição, resta aos professores-gestores buscar novas competências, permitindo atingir os objetivos de suas novas funções. Destarte, o critério político que foi determinante, inicialmente, poderá ser superado pelos resultados que venham a ser alcançados com a capacitação.

Ademais, em função da limitação desta pesquisa, que se restringiu à análise apenas de uma instituição de ensino superior e na perspectiva de quatro entrevistados, sugere-se futuras pesquisas que ampliem o escopo utilizado para outras instituições, considerando a perspectivamente de mais atores, acerca dessa temática que carece de estudos em maior profundidade.

\section{REFERÊNCIAS BIBLIOGRÁFICAS}

AMARAL, H. K. do. Desenvolvimento de competências de servidores na administração pública brasileira. Revista do Serviço Público. Brasília, v. 57, n. 4, p. 549-563, out./dez. 2006.

BERNARDES, J. F. As políticas de recursos humanos e suas influências na gestão universitária. In: III Colóquio Internacional sobre Gestão Universitária na América do Sul. Anais...Buenos Aires. 2003. 
BERNARDONI, D. L. Mapeamento de competências: um estudo de caso na Pró-Reitoria de Pesquisa e Pós-Graduação da Universidade Federal do Paraná. Dissertação de Mestrado em Gestão da Informação e do Conhecimento. 157 f. Universidade Federal do Paraná, 2010.

BORGES, M. C. Das funções de confiança stricto sensu e dos cargos em comissão: abordagem constitucionalmente adequada. Revista TCEMG. Belo Horizonte, v. 82, n. 1, p. 45-54, jan./mar. 2012.

BRASIL. Constituição Federal, de 05 de outubro de 1988. Brasília, DF, 05 out. 1988. Disponível em: <http://www.planalto.gov.br/ccivil_03/constituicao/constituicao.htm>. Acesso em: 12 jun. 2014.

BRASIL. Lei n.8112, de 11 de dezembro de 1990. Brasília, DF, 11 dez. 1990. Disponível em: <www.planalto.gov.br/ccivil_03/leis/18112cons.htm>. Acesso em: 15 jun. 2014.

BRESSER-PEREIRA, Luiz Carlos. Da administração pública burocrática à gerencial. Revista do Serviço Público, v. 47, n. 1, p. 7-40, 1996.

CAMPOS, D. C. et al. Competências Gerenciais Necessárias aos Professores-Gerentes que Atuam em Pró-Reitorias: o caso de uma Instituição Federal de Ensino Superior de Minas Gerais. In: XXXII Encontro ANPAD. Anais...Rio de Janeiro. Set. 2008.

CARVALHO, H. M. de. Criação e provimento dos cargos públicos comissionados e o controle pelo poder judiciário. Revista Âmbito Jurídico. Rio Grande, v. 14, n. 94, nov. 2011

DALFOVO, M. S.; LANA, R. A.; SILVEIRA, A. Métodos quantitativos e qualitativos: um resgate teórico. Revista Interdisciplinar Científica Aplicada, Blumenau, v.2, n.4, p.01-13, Sem II. 2008

DI PIETRO, M. S. Z. Direito Administrativo. 21 ed. São Paulo: Atlas, 2008

ENAP - ESCOLA NACIONAL DE ADMINISTRAÇÃO PÚBLICA. Apresentação. 2014. Disponível em: <http://www.enap.gov.br/>. Acesso em: 13. Jun. 2014.

GONÇALVES, Eliane Cristina Grecchi. A formação de docentes para o exercício de cargos de gestão na universidade. Dissertação de Mestrado em Gestão Empresarial. Fundação Getúlio Vargas. Rio de Janeiro. 2010.

GRAEF, A. Cargos em Comissão e Funções de Confiança: Diferenças conceituais e práticas. Processo de Revisão do Estatuto e do Regimento Geral. Universidade Federal de Uberlândia. 2010. Disponível em: <http://www.estatuto.ufu.br/>. Acesso em: 13 jun. 2014.

KANAN, L. A.; ZANELLI, J. C. Características do trabalho de coordenadores de curso no contexto universitário. REP. Passo Fundo, v. 18, n. 1, jan./jun. 2011

LOPES, F. D. Teoria Institucional e Gestão Universitária - uma análise do processo de avaliação institucional da UNIJUÍ. REAd. Porto Alegre, vol. 5, n. 4., dez, 1999.

MARRA, A. V.; MELO, M. C. de O. L. Docente-gerente: O Cotidiano de Chefes de Departamento e Coordenadores em uma Universidade Federal. 2003.

MPOG - MINISTÉRIO DO PLANEJAMENTO, ORÇAMENTO E GESTÃO. Manual de Orientação para Arranjo Institucional de Órgãos e Entidades do Poder Executivo 
Federal. 2008. Disponível em:

$<$ http://www.planejamento.gov.br/secretarias/upload/Arquivos/seges/090204_manual_arranjo institucional.pdf>. Acesso em: 14 jun. 2014.

MENDES, M. das G. C. Estratégias organizacionais e práticas de recursos humanos: um estudo de caso na universidade estadual do maranhão. Dissertação de mestrado em Administração. Universidade Federal de Santa Catarina. Florianópolis. 2001.

NEWCOMER, K. E. A preparação dos gerentes públicos para o século XXI. Revista do Serviço Público. Brasília, v. 50, n. 2, p. 05-18, abr./jun. 1999.

PAES DE PAULA, A. P. Administração pública brasileira entre o gerencialismo e a gestão social. Revista de Administração de Empresas. São Paulo, v. 45, n. 1, p. 36-49, janmar. 2005.

PALMEIRAS, J. de B.; SZILAGYI, R. S. Perfil e competências necessários para um coordenador de curso na percepção dos gestores e funcionários de uma IES. In: XI Colóquio Internacional sobre Gestão Universitária na América do Sul. Anais...Florianópolis, 2011.

PEREIRA, A. L. C.; SILVA, A. B. As competências gerenciais nas instituições federais de educação superior. CADERNOS EBAPE. BR.Rio de Janeiro, v. 9, Edição Especial, jul. 2011.

ROCHA, E. A. O CARGO DE CONFIANÇA NA JURISPRUDÊNCIA DO TST. Tribunal Regional do Trabalho da 9a Região. 2010. Disponível em:

$<$ http://www.trt9.jus.br/apej/artigos_doutrina_ear_01.asp>. Acesso em: 02 jul. 2014.

SAMPAIO, R. M.; LANIADO, R. N. Uma Experiência de mudança da gestão universitária: o percurso ambivalente entre proporções e realizações. RAP. São Paulo, v. 43, n.1, jan./fev. 2009.

SANTOS, L. A. dos. Burocracia profissional e a livre nomeação para cargos de confiança no Brasil e nos EUA. Revista do Serviço Público. Brasília, v. 60, n. 1, p. 05-28, jan./mar. 2009.

SILVA, F. M. V. da. A transição para a gestão universitária: o significado das relações interpessoais. R. Adm. FACES Journal. Belo Horizonte, v. 11, n. 4, out./dez. 2012.

SOUZA, N. B. de. Gestão estratégica e o binômio "aparato racional-legal" e "criatividade" na percepção dos dirigentes da Universidade Federal de Viçosa - UFV. Tese de Doutorado em Engenharia de Produção. Universidade Federal de Santa Catarina. Florianópolis. 2003

SMITH, G. S. Novos desafios para a capacitação de liderança de alto nível na gestão pública e governança em um mundo globalizante. Revista do Serviço Público. Brasília, v. 54, n. 2, p. 99-117, abr./jun. 2003.

TOHÁ, C.; SOLARI, R. A modernização do Estado e a gerência pública. Revista do Serviço Público. Brasília, v. 48, n. 3, p. 84-103, set./dez. 1997.

TORRES, M. D. de F. Estado, democracia e administração pública no Brasil. Reimpressão. Rio de Janeiro: Editora FGV, 2007. 